\title{
Rational Dialogue in the Era of Globalization: Transcending "Imagination" and "Prejudice" -- out of the Plight of International Communication of China's National Image
}

\author{
Yu Zhang \\ The College of Literature and Journalism of Sichuan University, Chengdu, Sichuan Province, China
}

Keywords: China's image; international communication; prejudice; rational dialogue

\begin{abstract}
This paper mainly analyzes the plight of advocating the image of China in the process of international communication, and finds out that the reason for this dilemma lying in people's imagination when watching the others come from distant areas. Non-objective imaginations exist in both western and eastern worlds when they watching each other. The imaginary and non-objective images are repeated in people's mind and become stereotypes, which are difficult to change. The conclusion of this paper is, under the new historical background of globalization, more objective mutual understandings between people and countries could be achieved through new media technology, communication modes and deep rational dialogue.
\end{abstract}

\section{Plight in the International Communication of China's National Image}

As far as the communication circle is concerned, the national image of a country is generally divided into two parts: domestic image and international image. But more scholars adopt the concept of international image, which is "the basic impression and overall evaluation of the public in international community on a country." [1] From my perspective, the image of a country not only contains macro aspects like political, economic and cultural impressions, but also includes the impression and view of people who live in the country. After the reform and development of China for more than thirty years, national economic strength of our country is greatly improved with the cultural and educational levels. The increase of people's wealth brought by economic growth greatly improved the confidence of Chinese people and deepened their recognition on the national image of China. But the international image of China cannot match its economic status. Difficulties occur in the international communication of the image of China.

Joshua Ramo, an American scholar which put forward to the concept of "Beijing consensus", pointed out in the book Brand China that the image of China in recent years (from 1997 to 2005) has greatly improved in Chinese people's own minds, but the image of China in foreigners' minds is totally different.

In the book of Brand China, it is pointed out that, Chinese people believe that we are easy to communicate, reliable and trustworthy. But foreigners hold that we are hard to communicate, unreliable and not trustworthy. In terms of health, values, quality and other indicators, Chinese people's scores are also very different from those of foreigners. [2]

Although Remer's analysis and relevant data show the situation of 10 years ago, many suggestions put forward in the book, including the transmission of both positive and negative sides and admitting existing problems, have been adopted by the Chinese government. The Chinese national image publicity film appeared in the New York Time Square in 2011. While promoting the positive image of China, the video also involves negative issues of China. But the promotional film was not as successful as expectation. Although the country has invested a series of manpower and material resources to improve the international image, the efforts achieved little success.

Generally speaking, China's national images exist in the international community in following forms: the backward China in the third world; the largest emerging market which offers countless opportunities; the ancient and mysterious China which represents the eastern civilization; China as the central state of superpower. The four basic impressions interact with each other, and construct 
several basic understandings of China, including the "China Threat Theory", "China Responsibility Theory", "China Collapse Theory", "Chinese Model Theory" and "China Irrelevance theory". [3] Elites view China as a huge market with fast economic growth, and hold different opinions on the development of "Chinese model". But most ordinary people do not understand the modern China. They regard China as a mysterious and antiquate country, and only have limited understanding on Chinese culture, such as Kung Fu Pandas.

\section{2. "Imagination" and "Prejudice": the Tradition of Watching the Others}

\subsection{Orientalism.}

If we expand the problem from a relatively small category of "Chinese image" in international community, and analyze how different regions, nations and countries watch each other, we will have better understandings on this problem.

The East is irrational, degenerate, naive and "abnormal", while Europe is rational, chastity, mature and "normal". [4] The citations come from Edward Said, a postcolonial cultural critic who wrote the book of Orientalism. In the book he analyzes and reveals that the so-called Orient is only the product of "imagination" and "construction" formed by western scholars. The aim of this concept is to achieve better political and cultural colonization, and meet the needs of European people to know about the East. Therefore, this whole set of understanding and interpretation of Orientalism is not objective. It is composed of arbitrary definitions and expressions on Orient from the perspective of western centralism, while the true Orient has lost the qualification of expression. Although Said used the word of Orient to represent the Middle East Arabia Muslim world in the book, the analysis and theory about "watching others" can be used in the study of other images.

In Said's view, "some special objects are created by brain. Seemingly objectively existed, they are actually from fictions. A group of people living in a particular area set up many boundaries for themselves, and divide the land into three parts: their own land, land closely adjacent to their own land, and land in remote areas; they call the remote area as the land of the barbarian." [5] People use the concept of others to understand the world which is far beyond their imagination. They use a series of imaginative descriptive words, such as "backward" "irrational" and "depravity" to define the others. Others even do not have the ability to defend themselves. In the Orientalism discourse system, Arabs are "degraded", "obese", "camel riding" and "greed" people.

In addition to negative imagination, there are many beautified imaginations on others. In the process of international communication, some people deliberately exaggerate the achievements of China, and ask China to take more international responsibilities; they even believe that China will dominate the world in twenty-first Century. [6]

\subsection{Occidentalism.}

The understanding of East in western world is full of imagination, while the understanding of the West in eastern world is full of stereotype imagination and even prejudice, too. "We also need to agree with Ian Buruma and Avishai Margalit that Orientals also have retaliatory imaginations and understandings on western world. The two authors created the concept of Occidentalism to analyze this phenomenon. They believe that there are "four sins" in western world: 1. Cities are full of evil, but Westerners like to live in busy cities. They are rootless, greedy and decadent. 2. They know science and reason, but they do not have real faith, and believe in materialism. 3. Bourgeoisie are mercenary and against others to be chivalric. There is no heroic spirit at all. During the war, they usually surrender easily. No one lays down his life for a just cause. 4. the most abominable things are pagans and "non - believers". People who do not believe in anything, or worship evil forces but ignore the true God are the root of a chaotic country and even a turbulent world. "[7] A series of familiar negative words such as "evil, greed and mercenary" are used to describe the west in that context.

The experience and knowledge about the others formed through simple imaginations which can become fixed stereotypes; stereotypes make us unable to obtain deep and objective understandings of things. As Said pointed out, the westerners' imaginations and perceptions on East depend largely on 
the model provided by "Orientalism". The model makes it difficult for western people to understand the constantly evolving reality of Eastern world. Therefore, even if they find out that the Orient they see in our own eyes vary from the Orient described in traditional books and the Orient in their minds, it is difficult for them to believe what they have seen. We tend to believe in the East that we have imagined, and the East which is described by traditional scholars in books. People cannot accept or objectively view new changes during the development of things if they are contrary to our own experience. This is what Lippmann called "Prejudice". That is, as Lippmann said, "in most cases, we do not first understand and then define, but first define and then understand. In a complex and noisy external world, we can understand our own culture easily, in which the definition of different things have been provided. We also tend to understand the world through familiar and given ways. "[8]

\section{Rational Dialogue in the Era of Globalization: Beyond "Imagination" and "Prejudice"}

If we throw away the negative imagination of the others exist in our ideology, we can use the greatest kindness to explain the irrational imagination formed in the process of image transmission. The reason for un objective expression lies in distance and the lack of personal experience.

Lippmann proposed a concept of "mimicry environment", he believes that between human and real environment, there is a "mimicry environment" created by the mass media, because "the real environment is too large, too complex and changes too fast. We are not prepared to cope with such a wonderful, diversified and ever-changing world. " [9] In the global era, due to the emergence of new media, the development of Internet and other communication media, especially the development of self-media represented by Twitter, Facebook as well as micro-blog and WeChat in China, people can better known persons come from different countries and regions. The convenience and cheapness of transportation also make it easy for people to go to the world of others.

Zsigmon Bowman said, "at the moment, all of us are moving." Such a statement is a bit exaggerated, but the number of people who engage in transnational tourism and business, people who study abroad and immigrate, and the number of refugees have increased at an alarming rate. In 2005, there were 220 million tourists around the world. The World Tourism Organization estimates that by 2020, the number of visitors will reach 350 million. In 2005, there were 185 million transnational immigrants all over the world. [10] Chinese travel agencies believe that in China, the number of potential transnational tourists is up to 300 million, and the number of outbound tourists is as many as 40 million people each year. In the past, the image of "Orient" or "China" is still dependent on books or adventurer stories; but now, the image of our country come from the real contacts among people. Therefore, the development of traffic, communication and media in the era of globalization provides a opportunity for people who want to know the "Others"; such an opportunity can help the communication of the Chinese image in the world.

In the face of differences and objections, how to eliminate stereotypes, how to understand things as objectively as possible, and how to reach the truth, are problems we need to analyze. In this paper, Habermas's "communicative rationality" is used to carry out analysis and inquiry. The communicative rationality is "based on language behavior, various subjects in the communication community try to achieve the goal of mutual acceptance with mutual understanding and coordination." [11] In order to overcome the gap between different interests groups and ease the conflict between self-interests and social interests, and realize the rationality of communication, the way of "discourse debate" is needed. Habermas' theory is established in the historical environment of the turning from post-modern philosophy to linguistics, so he hopes to establish an ideal discourse environment through the authenticity, correctness and sincerity of speech act. "In this discourse environment, all the subjects have the right to participate in the argument; anyone can express their views freely or put forward to their objections; all discourse participants have equal rights to explain, suggest, and argue. No one should be suppressed. [12] Therefore, in Habermas's view, in the multiculturalism environment today, we can guarantee the coexistence of different races and cultures on the basis of voluntary alliance, and achieve the rational communication between subjects through the method of discourse argument in a well functioned public domain. 


\section{Conclusion}

In the era of globalization, the new media and communication equipment provide us a new opportunity to break traditional "stereotypes" exist between the West and East. Through more contacts between people and more deep discussions, prejudices could be eliminated; truly understand and mutual trust could be built. Only in this way can we build a better ecological environment for the international communication of the image of China, and help different countries and regions to understand each other more deeply. The method helps us to break imagination and stereotypes, and help foreigners to form more objective and deeper understandings on the real situation of China.

\section{Acknowledgement}

Fund Project: This paper is one of the outcomes of the research, The Communication and Accept ance of China's Image in Europe, which is supported by the Foundation for Basic Scientific Researc h Projects in 2016. Yu Zhang is the director of this project. Project No.: 2082704194136.

\section{References}

[1] Z.K. Jin, Q.C. Xu, The shaping of national image: a new topic of Chinese diplomacy, J. Journal of Renmin University of China, 2 (2010).

[2] J. C. Ramo, Brand China, Foreign Policy Centre, London.

[3] X.Y. Zhou, How does China Advocate Herself, People's Publishing House, Beijing.

[4] [5] E. W. Said, Orientalism, SDX Joint Publishing Company, Beijing, 2011.

[6] H. Kissinger, et. al., Does the Twenty-first Century Belong to China? CITIC Press Group, Beijing. 2012.

[7] F. Wu, Being-with-Others: beyond the dualistic thought of "we" and "you", J. Journalism and Communication. 10 (2013).

[8] [9] W. Lippmann, Public Opinion, Shanghai Remin Publishing House, Shanghai, 2006.

[10] T.H. Eriksen, The Key Concepts of Globalization, Yilin Press, Nanjing. 2012.

[11] Q. Gong, Reconstruction of Moral Utopia: Research on the Communicative Ethics of Jürgen Habermas, The Commercial Press, Beijing, 2005.

[12] X.S. Zheng, Technology and Rationalization: Research on the Philosophy of Technology of Habermas, Qilu Press, Jinan, 2007. 